\title{
Corrigendum: The Dental Team: An Additional Resource for Delivering Vaccinations
}

\author{
Stefan Serban ${ }^{1,2 *}$, Zhain Mustufvi ${ }^{1}$, Jing Kang ${ }^{1}$, Sally Eapen Simon ${ }^{2}$, Siobhan Grant ${ }^{2}$ and \\ Gail Douglas ${ }^{1}$
}

${ }^{1}$ School of Dentistry, University of Leeds, Leeds, United Kingdom, ${ }^{2}$ Public Health England, North East and Yorkshire Regional Office, Leeds, United Kingdom

Keywords: COVID-19, coronavirus, dentistry, dental team, vaccinations, influenza, flu, immunisation

\section{A Corrigendum on}

The Dental Team: An Additional Resource for Delivering Vaccinations by Serban, S., Mustufvi, Z., Kang, J., Simon, S. E., Grant, S., and Douglas, G. (2020). Front. Med. 7:606242. doi: 10.3389/fmed.2020.606242

\section{OPEN ACCESS}

Approved by:

Frontiers Editorial Office,

Frontiers Media SA, Switzerland

*Correspondence:

Stefan Serban

s.t.serban@leeds.ac.uk

Specialty section:

This article was submitted to Infectious Diseases - Surveillance,

Prevention and Treatment,

a section of the journal

Frontiers in Medicine

Received: 15 January 2021

Accepted: 10 February 2021

Published: 25 March 2021

Citation:

Serban S, Mustufvi Z, Kang J, Simon SE, Grant $S$ and Douglas G (2021) Corrigendum: The Dental

Team: An Additional Resource for

Delivering Vaccinations.

Front. Med. 8:653861.

doi: 10.3389/fmed.2021.653861
In the original article, there was an error. The examples of countries where dentists can deliver flu vaccinations included New Zealand. This is a mistake as New Zealand should not have been on that list.

A correction has been made to the Delivery Methods, Flu vaccinations, Subsection One-StopShop:

"Patients could choose to receive their influenza vaccine at the same time as their dental appointment. This model would support the principle of reduction of the number of contacts between patients and healthcare settings and reduce the risks associated with multiple journeys, especially in more rural areas where traveling longer distances is often required. It could be done both opportunistically as well as in a targeted manner for specific cohorts. This approach has already been successfully implemented in certain states in the US (13)."

Reference 23 was also removed from the reference list.

The authors apologize for this error and state that this does not change the scientific conclusions of the article in any way. The original article has been updated.

\section{REFERENCES}

13. Simon L, editor. How Will Dentistry Respond to the Coronavirus Disease 2019 (COVID-19) Pandemic?. JAMA Health Forum. American Medical Association (2020).

Copyright (c) 2021 Serban, Mustufvi, Kang, Simon, Grant and Douglas. This is an open-access article distributed under the terms of the Creative Commons Attribution License (CC BY). The use, distribution or reproduction in other forums is permitted, provided the original author(s) and the copyright owner(s) are credited and that the original publication in this journal is cited, in accordance with accepted academic practice. No use, distribution or reproduction is permitted which does not comply with these terms. 